\title{
Crescimento e estado nutricional de helicônia irrigada com água residuária tratada em casa de vegetação
}

\author{
Olívia S. N. Santos ${ }^{1}$, Vital P. da S. Paz ${ }^{2}$, Thomas V. Gloaguen ${ }^{3}$, \\ Marcelo B. Teixeira ${ }^{4}$, Francisco de S. Fadigas ${ }^{3}$ \& João A. Costa ${ }^{3}$
}

\begin{abstract}
RESUMO
Neste trabalho se estudaram o desenvolvimento e o estado nutricional de helicônias irrigadas com água residuária tratada de origem doméstica associada a fertilizantes químicos (NPK). O experimento foi conduzido em casa de vegetação na qual se utilizaram plantas de helicônia Golden Adrian. O experimento foi instalado no esquema fatorial $5 \times 3+1$ constituídos de cinco níveis de lâmina de água aplicada (equivalente a 60, 80, 100, 120 e 140\% da evaporação do tanque classe A ECA), três tipos de água (água residuária (AR), água pluvial (AP) e mistura de $50 \%$ de $A R+50 \%$ de AP) e testemunha (solo sem adubação e recebendo $100 \%$ da ECA de água pluvial). O delineamento experimental utilizado foi blocos ao acaso, com cinco repetições. A utilização de AR e as lâminas maiores proporcionaram acréscimo nos parâmetros de crescimento avaliados. Os teores de macronutrientes presentes nas folhas das plantas irrigadas com AR se comportaram de forma semelhante às plantas que receberam AP. O uso de AR e AP resultou em acréscimo de teores de micronutrientes nas folhas, principalmente Fe e $\mathrm{Mn}$, acima dos teores recomendados para a cultura.
\end{abstract}

Palavras-chave: reúso de água, nutrientes, lâmina de irrigação

\section{Growth and nutritional status of helicônia irrigated with treated wastewater in greenhouse}

\begin{abstract}
In this study the growth and nutritional status of helicônias irrigated with treated wastewater of domestic origin associated with chemical fertilizers (NPK) was studied. The experiment was conducted in a greenhouse utilizing plants of helicônia Golden Adrian. The experiment was installed in $5 \times 3+1$ factorial scheme consisting of five depths of irrigation water (equivalent to 60, 80, 100, 120 and 140\% of class A pan evaporation - ECA), three types of water (wastewater (AR), rainwater (AP) and a mixture of $50 \%$ $A R+50 \% A P$ ) and control (soil without fertilizer and receiving rainwater corresponding to $100 \% \mathrm{ECA}$ ). The experimental design was in randomized blocks with five repetitions. The use of AR and larger depths of irrigation provided increases in evaluated parameters of growth. The levels of macronutrients in the leaves of plants irrigated with AR were similar to plants that received AP. The use of AR and AP resulted in increases in the content of micronutrients in leaves, especially Fe and $\mathrm{Mn}$, above the levels recommended for the crop.
\end{abstract}

Key words: reuse of water, nutrients, irrigation depth

\footnotetext{
${ }^{1}$ Núcleo de Engenharia de Água e Solo/UFRB. E-mail: olivianepomuceno@gmail.com

${ }^{2}$ Centro de Ciências Agrárias, Biológicas e Ambientais/UFRB, CEP 44380-000, Cruz das Almas, BA. Fone: (75) 3361-2798. E-mail: vpspaz@ufrb.edu.br ${ }^{3}$ Centro de Ciências Exatas e Tecnológicas/UFRB, CEP 44380-000, Cruz das Almas, BA. Fone: (75) 3361-2021. E-mail: gloaguen@gmail.com; fadigas@ufrb.edu.br; albany@ufrb.edu.br;

${ }^{4}$ Graduando em Agronomia/UFRB. Bolsista PET/SESu/MEC. E-mail: marcelo-bt@bol.com.br
} 


\section{INTRODUÇÃO}

O desenvolvimento gerado pelo homem tem desfeito o conceito de que a disponibilidade hídrica é abundante e ilimitada, o que tem levado as questões sobre qualidade e economia da água, a se tornarem cada vez mais importantes no contexto da gestão ambiental e da engenharia de irrigação.

O aumento do consumo de água e de alimentos no mundo tem sido impulsionado pelo aumento do padrão de consumo e pelo crescimento das diversas atividades humanas que através das diversas formas de poluição, afetam a disponibilidade de água potável, tornando-a cada vez mais escassa, o que faz do reúso de água uma alternativa bastante atrativa na área sobtetudo agrícola, o que tem estimulado a realização de diversas pesquisas por todo o mundo (Ammary, 2007; Rutkowski et al., 2007; Walker \& Lin, 2008; Qadir et al., 2010). Segundo Murray \& Ray (2010) pesquisas realizadas em vários países demonstram que o aproveitamento da água residuária para fins agrícolas apresenta benefícios econômicos e ambientais, advindos dos nutrientes incorporados nas águas residuais, podendo aumentar os rendimentos tanto ou mais, quando comparado ao uso de fertilizantes químicos.

O reúso de águas ainda necessita de estudos específicos concernentes às suas técnicas de aplicação, sobremaneira em países em desenvolvimento, nas quais a infraestrutura sanitária existente é, em geral, muito deficiente.

Tendo em vista os benefícios às limitações da irrigação de culturas com águas residuárias, faz-se necessário o manejo adequado e controlado, avaliando suas características e levando em consideração o tipo da cultura, o solo e a forma como esse produto será consumido. Neste contexto, o uso de efluentes na irrigação de plantas ornamentais possui grande potencial como alternativa viável ambiental e economicamente.

Atualmente, a floricultura é um setor por demais competitivo, poís exige a utilização de tecnologias avançadas, profundo conhecimento técnico pelos produtores e um sistema eficiente de distribuição e comercialização. Dentre as plantas ornamentais cultivadas no Brasil a helicônia se destaca por apresentar características que possibilitam seu cultivo em diversas partes da região Nordeste, bastando observar os microclimas privilegiados, a disponibilidade de terra, água, mão-de-obra e tecnologias agronômicas. Esta espécie vêm apresentando crescente comercialização no mercado internacional, em função do aumento da área de produção nos países da América Central e da América do Sul, proporcionando uma oferta maior e, consequentemente, sua divulgação (Santos et al., 2006). Embora apresentem grande potencial de comercialização, as pesquisas relacionadas à demanda nutricional ainda são escassas, apesar da suma importância da adubação para a produção e manejo pós-colheita (Castro et al., 2007).

Objetivou-se, neste trabalho, estudar o desenvolvimento e o estado nutricional de plantas de Helicônia Golden Torch
Adrian, irrigadas com água residuária tratada, cultivadas em vaso em casa de vegetação.

\section{Material e MÉTOdos}

O experimento foi conduzido em casa de vegetação, no período de março a setembro de 2009, na área experimental do Núcleo de Engenharia de Água e Solo da Universidade Federal do Recôncavo da Bahia, localizado no município de Cruz das Almas, BA, na latitude de $22^{\circ} 42^{\prime} \mathrm{S}$, longitude $47^{\circ} 38^{\prime} \mathrm{W}$ e altitude de $220 \mathrm{~m}$. O clima da região é classificado como úmido a subúmido, com umidade relativa e temperatura média anual de $80 \%$ e $24{ }^{\circ} \mathrm{C}$, respectivamente e pluviosidade média anual de $1.143 \mathrm{~mm}$ (D’Angiolella et al., 1998).

O delineamento experimental utilizado foi em blocos ao acaso (cinco blocos) em esquema fatorial $5 \times 3+1$. Os tratamentos consistiram de cinco lâminas de água aplicada (equivalente a $60,80,100,120$ e $140 \%$ da evaporação do tanque classe A ECA), três tipos de água (água residuária (AR), água pluvial (AP) e mistura contendo $50 \% \mathrm{AR}+50 \% \mathrm{AP}$ ) e testemunha (solo sem adubação e recebendo lâmina equivalente a $100 \%$ da ECA com água pluvial). Utilizou-se uma planta por parcela com cinco repetições, totalizando 80 parcelas experimentais.

O solo utilizado foi coletado na camada $0-20 \mathrm{~cm}$ no campus da UFRB e classificado, por Carvalho et al. (2002) como Latossolo Amarelo coeso A moderado, de baixa fertilidade e apresentando horizontes subsuperficiais coesos.

O solo foi seco ao ar e posteriormente retirada uma amostra para análise química (Tabela 1), realizada no Laboratório de Solos da Empresa Baiana de Desenvolvimento Agrícola (EBDA).

Utilizaram-se plantas de helicônia cultivar Golden Torch Adrian, com três meses de idade, que passaram por processo de limpeza para remoção de solo e do excesso de raízes e depois imersas em água contendo $1 \%$ de solução de hipoclorito de sódio, por $3 \mathrm{~min}$, para desinfestação. O plantio foi realizado em vasos com capacidade de $20 \mathrm{~L}$, nos quais foram adaptados conectores e uma mangueira interligando o vaso a uma garrafa, com capacidade de $2 \mathrm{~L}$, para coletar a água de drenagem. Os vasos foram preenchidos com solo (aproximadamente $15 \mathrm{~L}$ ) sob uma camada de brita de $3 \mathrm{~cm}$.

Adubações orgânica e química foram realizadas, a primeira no plantio, que consistiu na adição de $1,5 \mathrm{~L}$ de esterco de curral curtido, homogeneizado ao solo, equivalendo a $10 \%$ do volume total de solo do vaso, conforme recomendação de Kämpf et al. (2006) e a segunda foi realizada com base na recomendação de Sousa (2006) e constou da aplicação de 150, 50 e $125 \mathrm{mg}$ de NPK kg-1 de solo, respectivamente, utilizandose nitrato de cálcio, superfosfato simples e sulfato de potássio. A adubação foi fracionada aos 30, 60 e 90 dias, levando-se em consideração os nutrientes da água residuária; para tanto, procedeu-se à análise de uma amostra da água para determinação

Tabela 1. Análise química do solo utilizado no experimento

\begin{tabular}{|c|c|c|c|c|c|c|c|c|c|c|}
\hline \multirow{2}{*}{$\begin{array}{c}\mathrm{pH} \\
\text { (água) }\end{array}$} & \multirow{2}{*}{$\begin{array}{c}P \\
\left(\mathrm{mg} \mathrm{dm}^{-3}\right)\end{array}$} & C & M.0. & $\bar{K}$ & $\mathrm{Ca}$ & $\mathrm{Mg}$ & $\mathrm{H}+\mathrm{Al}$ & Al & $\mathrm{Na}$ & CTC \\
\hline & & \multicolumn{2}{|c|}{$\left(\mathrm{g} \mathrm{kg}^{-1}\right)$} & \multicolumn{7}{|c|}{$\left(\mathrm{mmol}_{\mathrm{c}} \mathrm{dm}^{-3}\right)$} \\
\hline 5,1 & 12 & 6,5 & 11,2 & 1,0 & 7,1 & 7,2 & 30,4 & 1,5 & 0,2 & 45,9 \\
\hline
\end{tabular}


dos teores de nitrogênio, fósforo e potássio (Tabela 2). Através dos valores obtidos estimou-se o aporte de nutrientes ao longo do ciclo. A adubação química foi realizada tomando-se como base o valor obtido pela diferença entre os teores de nutrientes fornecidos pela água residuária tratada e a recomendação para a cultura.

Tabela 2. Características da água pluvial e residuária (efluente) utilizados na irrigação

\begin{tabular}{lccr}
\hline Determinações & Unidade & \multicolumn{1}{c}{ Água } & \multicolumn{1}{c}{ Efluente } \\
pH & & 6,7920 & 7,7660 \\
Condutividade elétrica & $\mathrm{dS} \mathrm{m}^{-1}$ & 0,0219 & 0,5348 \\
Amônia $\left(\mathrm{NH}_{4}^{+}\right)$ & $\mathrm{mg} \mathrm{L}^{-1}$ & 0,2980 & 12,5712 \\
Nitrito $\left(\mathrm{NO}_{2}^{-}\right)$ & $\mathrm{mg} \mathrm{L}^{-1}$ & 0,0046 & 0,1722 \\
Nitrato $\left(\mathrm{NO}_{3}^{-}\right)$ & $\mathrm{mg} \mathrm{L}^{-1}$ & 0,4517 & 13,0754 \\
Sulfato $\left(\mathrm{SO}_{4}^{2-}\right)$ & $\mathrm{mg} \mathrm{L}^{-1}$ & 5,6730 & 60,0884 \\
Fósforo disponível & $\mathrm{mg} \mathrm{L}^{-1}$ & 0,0972 & 4,2453 \\
Potássio & $\mathrm{mg} \mathrm{L}^{-1}$ & 0,4571 & 11,6202 \\
Sódio & $\mathrm{mg} \mathrm{L}^{-1}$ & 1,3714 & 57,1901 \\
Cálcio & $\mathrm{mg} \mathrm{L}^{-1}$ & 0,0000 & 5,6388 \\
Magnésio & $\mathrm{mg} \mathrm{L}^{-1}$ & 0,0000 & 8,0000 \\
Sólidos totais & $\mathrm{mg} \mathrm{L}^{-1}$ & - & 111,1120 \\
\hline
\end{tabular}

A água residuária, de origem doméstica, empregada no experimento, foi proveniente da Estação de Tratamento de Esgoto (ETE) da Empresa Baiana de Água e Saneamento (EMBASA) do município de Cachoeira, BA; a água não foi submetida a nenhum tipo de tratamento posterior, exceto o realizado na ETE, através de sistema de lagoas de decantação. De acordo com as diretrizes para interpretar a qualidade da água de irrigação descrita por Ayers \& Westcot (1991), o efluente utilizado se encontra na faixa normal de $\mathrm{pH}$ e sua conditividade elétrica não apresenta qualquer restrição de uso $\left(<0,7 \mathrm{dS} \mathrm{m}^{-1}\right)$.

Antes do plantio o solo foi elevado à capacidade de campo, utilizando-se água pluvial, e irrigado com $100 \%$ da ECA durante 30 dias; após este período deu-se início à aplicação dos tratamentos estabelecendo-se o turno de rega de dois dias; a irrigação foi realizada de forma manual, com o uso de proveta volumétrica; as parcelas experimentais foram alocadas em bancadas, com $50 \mathrm{~cm}$ de distância entre os vasos.

Foram monitoradas, mensalmente, as seguintes variáveis: altura da planta, diâmetro do pseudocaule, número de folhas e número de perfilhos.

Após o término do experimento as plantas foram divididas em parte aérea (folhas, pseudocaule e perfilhos) e subterrânea (raízes, rizoma e perfilhos que não foram emitidos), para obtenção das respectivas massas fresca e seca; a massa seca foi determinada mediante secagem em estufa com circulação forçada de ar a $70{ }^{\circ} \mathrm{C}$, até atingirem peso constante; por fim, foram considerados parte aérea as folhas, o pseudocaule e os perfilhos.

Para realização da análise foliar foram coletadas as folhas um, três e cinco (totalmente expandidas, contadas a partir do ápice) que, após identificação, foram acondicionadas em sacos de papel e levadas à estufa de circulação forçada de ar a $70^{\circ} \mathrm{C}$ durante $72 \mathrm{~h}$. As amostras foram analisadas no Laboratório de Solos e Nutrição de Plantas da Comissão Executiva do Plano da Lavoura Cacaueira (CEPLAC) para determinação das concentrações de N, P, K, Ca, Mg, Fe, Zn, Cu e Mn, segundo a metodologia de Malavolta et al. (1997).
A determinação da área foliar foi realizada através do método do disco foliar com diâmetro de $1,1 \mathrm{~cm}$, cujo resultado foi obtido através da equação:

$$
\mathrm{AF}=\frac{\mathrm{AD} \mathrm{MSF}}{\mathrm{MSD}}
$$

em que:

$$
\begin{aligned}
& \mathrm{AF} \text { - área foliar, } \mathrm{cm}^{2} \\
& \mathrm{AD} \text { - área do disco, } \mathrm{cm}^{2} \\
& \mathrm{MSF} \text { - massa seca da folha, } \mathrm{g} \\
& \text { MSD - massa seca do disco, } \mathrm{g}
\end{aligned}
$$

Os dados referentes ao crescimento das plantas e á análise foliar foram submetidos à análise de variância e as médias para os tipos de água foram comparadas pelo teste de Tukey a nível de 0,05 de probabilidade; para as lâminas realizou-se análise de regressão e se utilizou o programa estatístico SAEG.

\section{RESULTADOS E DISCUSSÃO}

Na Tabela 3 são apresentados os testes de média dos parâmetros de crescimento da planta, em função do tipo de água.

Pode-se verificar diferença significativa entre os tipos de água para todos os parâmetros avaliados, exceto número de perfilhos, e que as plantas irrigadas com AR e lâmina de $140 \%$ da ECA, apresentaram os maiores valores médios para altura, diâmetro do pseudocaule e número de folhas; os menores valores entre os parâmetros avaliados foram observados nas plantas que receberam lâmina de $60 \%$ da ECA, assemelhandose ao tratamento testemunha.

Contrário aos resultados obtidos nesse trabalho, Cerqueira et al. (2008), avaliando a resposta da helicônia Golden Torch à aplicação de esgoto doméstico e água de riacho, não encontraram diferença significativa entre os tipos de água havendo, contudo, altura maior para as plantas irrigadas com esgoto doméstico. Medeiros et al. (2007), por sua vez, estudando o uso de água residuária e o manejo convencional com água de abastecimento no cultivo de gérberas (Gerbera jamesonii), verificaram que as lâminas de água residuária que suplantaram as necessidades hídricas das plantas, não apresentaram quaisquer benefícios adicionais.

De acordo com a Tabela 3 observa-se que as lâminas maiores proporcionaram melhor desenvolvimento das plantas, independente do tipo de água. Não foi verificada interação significativa entre as lâminas aplicadas e os tipos de água, para os parâmetros de crescimento avaliados.

O melhor desenvolvimento, observado nas plantas que receberam água residuária e mistura, pode estar relacionado ao fracionamento do fornecimento de nutrientes visto que todas as plantas receberam as mesmas doses de NPK diferindo, entretanto, na quantidade da adubação química, pois nas plantas irrigadas com água residuária levou-se em consideração $\mathrm{o}$ aporte de nutrientes fornecidos pela água. $\mathrm{O}$ fracionamento 
Tabela 3. Efeito dos tipos de água nos parâmetros de análise de crescimento das plantas, aos 180 dias após o plantio

\begin{tabular}{|c|c|c|c|c|c|c|}
\hline \multirow{2}{*}{ Tipo de água } & \multicolumn{5}{|c|}{ Lâmina (\% ECA) } & \multirow{2}{*}{ Média } \\
\hline & 60 & 80 & 100 & 120 & 140 & \\
\hline $\begin{array}{l}\text { Água residuária } \\
\text { Água pluvial } \\
\text { Mistura } \\
\text { Média } \\
\text { Testemunha }\end{array}$ & $\begin{array}{l}56,30 \\
51,66 \\
58,00 \\
55,32\end{array}$ & $\begin{array}{l}59,40 \\
59,10 \\
59,50 \\
59,33\end{array}$ & $\begin{array}{c}\text { Altura (cn } \\
64,00 \\
57,10 \\
59,34 \\
60,15 \\
47,94\end{array}$ & $\begin{array}{l}63,70 \\
61,66 \\
64,06 \\
63,14\end{array}$ & $\begin{array}{l}73,30 \\
63,60 \\
70,06 \\
68,99\end{array}$ & $\begin{array}{l}63,34 \mathrm{a} \\
58,62 \mathrm{~b} \\
62,19 \mathrm{ab} \\
\\
47,94 \mathrm{c}\end{array}$ \\
\hline \multicolumn{7}{|c|}{ Diâmetro do pseudocaule (cm) } \\
\hline Água residuária & 1,30 & 1,35 & 1,42 & 1,38 & 1,58 & $1,41 \mathrm{a}$ \\
\hline Água pluvial & 1,22 & 1,26 & 1,22 & 1,33 & 1,40 & $1,29 b$ \\
\hline Mistura & 1,22 & 1,37 & 1,42 & 1,41 & 1,50 & $1,38 a b$ \\
\hline Média & 1,25 & 1,33 & 1,35 & 1,37 & 1,49 & \\
\hline Testemunha & & & 1,21 & & & $1,21 \mathrm{c}$ \\
\hline \multicolumn{7}{|c|}{ Número de perfilhos } \\
\hline Áqua residuária & 2,20 & 2,60 & 4.00 & 5,80 & 6.00 & $4,12 \mathrm{a}$ \\
\hline Água pluvial & 2,60 & 3,60 & 4,20 & 4,20 & 5,80 & $4,08 \mathrm{a}$ \\
\hline Mistura & 2,00 & 3,20 & 4,40 & 5,20 & 6,00 & $4,16 \mathrm{a}$ \\
\hline Média & 2,27 & 3,13 & 4,20 & 5,07 & 5,93 & \\
\hline Testemunha & & & 2,00 & & & $2,00 \mathrm{~b}$ \\
\hline \multicolumn{7}{|c|}{ Número de folhas } \\
\hline Água residuária & 8,00 & 12,00 & 18,20 & 22,00 & 23,80 & $16,80 \mathrm{a}$ \\
\hline Água pluvial & 8,00 & 9,60 & 15,40 & 17,60 & 19,60 & $14,04 \mathrm{~b}$ \\
\hline Mistura & 8,00 & 8,80 & 14,00 & 20,60 & 23,00 & $14,88 a b$ \\
\hline Média & 8,00 & 10,13 & 15,87 & 20,07 & 22,13 & \\
\hline Testemunha & & & 10,00 & & & $10,00 \mathrm{c}$ \\
\hline
\end{tabular}

Médias seguidas das mesmas letras não diferem entre si pelo teste de Tukey $(P<0,05)$

da adubação apresenta benefícios uma vez que os fertilizantes na água de irrigação são aplicados nos locais de maior absorção e prontamente acessíveis às plantas e, ainda, que perdas gasosas ou por escorrimento superficial são minimizadas (Teixeira et al., 2007).

Nobre et al. (2010) avaliando a produção do girassol, variedade Embrapa 122/V-2000, sob diferentes lâminas com efluentes domésticos e adubação orgânica, observaram que a reposição da necessidade hídrica com água residuária favoreceu o desenvolvimento das plantas, quando utilizada lâmina de 120\%; entretanto, Figueiredo et al. (2005), estudando a aplicação de diferentes lâminas de irrigação na produtividade da bananeira Prata Anã (Musa paradisiaca L.), não constataram diferença na produtividade com o acréscimo das lâminas.

Para as variáveis massa seca da parte subterrânea e folha não houve diferença significativa entre os tipos de água; entretanto, as plantas que receberam água residuária, independente da lâmina, apresentaram melhor desenvolvimento (Figura 1); para massa seca da parte aérea a AR diferiu estatisticamente dos demais tipos de água, tal como do tratamento testemunha, que apresentou massa de $0,018 \mathrm{~kg}$; observou-se que, independente do tipo de água, as lâminas proporcionaram acréscimo na massa seca da parte aérea e total havendo, porém, diferença significativa entre os tipos de água também para a massa total, caso em que os maiores valores foram observados no tratamento no qual foi realizada irrigação com AR e mistura. A massa seca total de todos os tratamentos também diferiu do tratamento testemunha, visto que apresentou massa de $0,0459 \mathrm{~kg}$.

Comportamento semelhante foi observado por Aiello et al. (2007) avaliando o efeito da irrigação com água residuária no cultivo de tomate, ao notaram que a produtividade do tomateiro aumentou quando irrigado com água residuária. Galbiatti et al. (2007), no entanto, não observaram diferenças marcantes quanto à utilização com água residuária ou tratada na irrigação de alface.

A área foliar (Figura 2), independente da lâmina de água aplicada, apresentou maiores resultados nas plantas irrigadas com água residuária, exceto para lâmina correspondente a $60 \%$ de ECA não havendo, entretanto, diferença significativa entre a mistura e a água pluvial. A maior área foliar foi verificada no tratamento que recebeu água residuária e lâmina de $140 \%$ da ECA $\left(0,2300 \mathrm{~m}^{2}\right)$. O menor valor foi observado no tratamento que recebeu água pluvial e lâmina de $60 \%$ da ECA $\left(0,0540 \mathrm{~m}^{2}\right)$, seguido do tratamento testemunha, que apresentou $0,0569 \mathrm{~m}^{2}$.

Castro (2007), avaliando a deficiência de macronutrientes em planta de helicônia Golden Torch obteve, para o tratamento completo, valores médios de área foliar de 0,2991 m²; o autor adotou outra metodologia, na qual a área foliar foi estimada multiplicando-se o produto do comprimento e da largura da folha por 0,4; observa-se, com isto, que a diferença com os valores aqui apresentados podem estar relacionados à diferença entre os métodos utilizados nesta determinação.

Ao término das avaliações na casa de vegetação as plantas se encontravam com nove meses de idade, período no qual florescera apenas uma planta. Castro (2007) cita que o florescimento das helicônias da espécie H. psittacorum ocorre a partir do sexto mês após o plantio. Vários fatores podem levar ao atraso da floração; ambientais, como umidade, temperatura, luminosidade ou endógenos, como nutrição e hormônios vegetais. Os baixos teores de $\mathrm{P}$ encontrados nas folhas podem ser um indicativo de que esses teores possam ter propiciado o atraso do florescimento, uma vez que os teores de $\mathrm{N}$ estão próximos dos encontrados por outros autores (Cerqueira et al., 2008; Castro, 2007; Sousa, 2006). 
A.

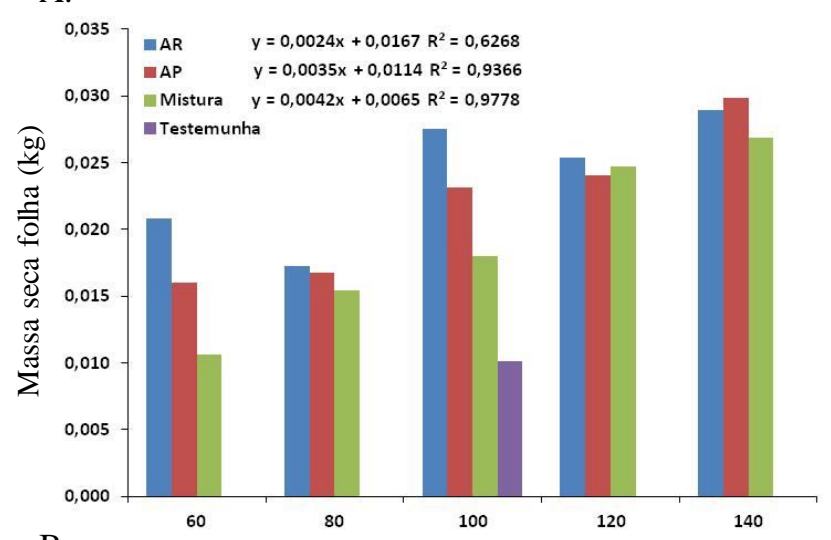

B.

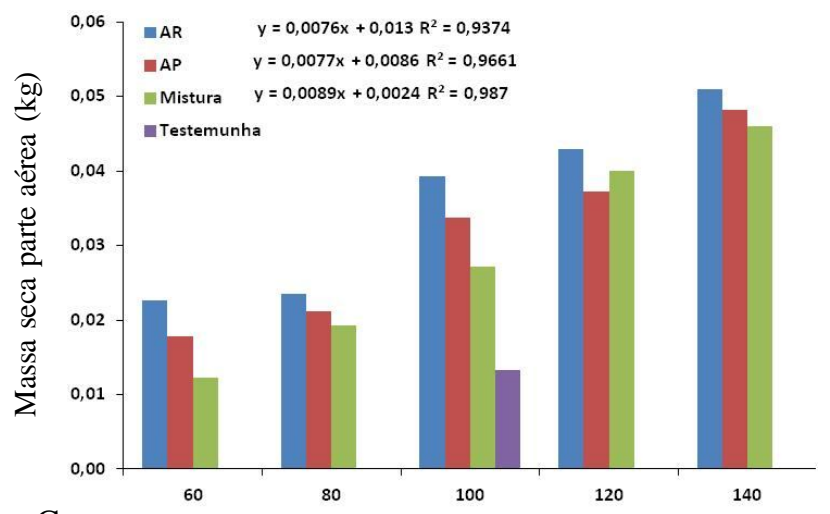

C.

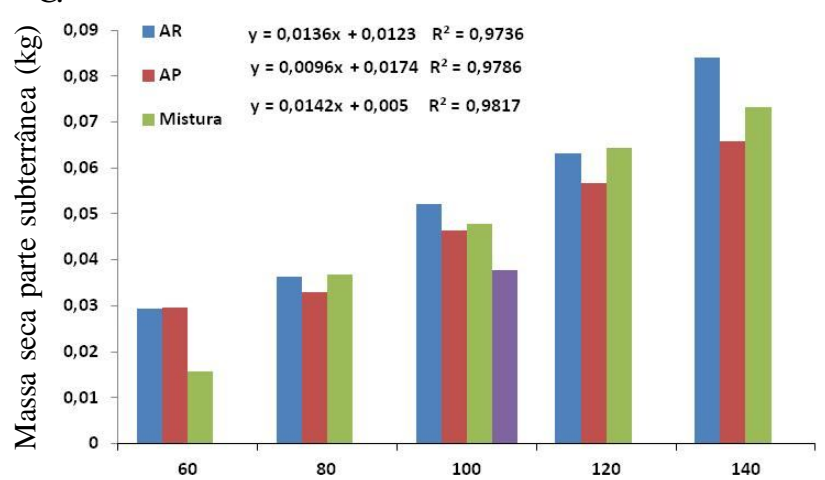

D.

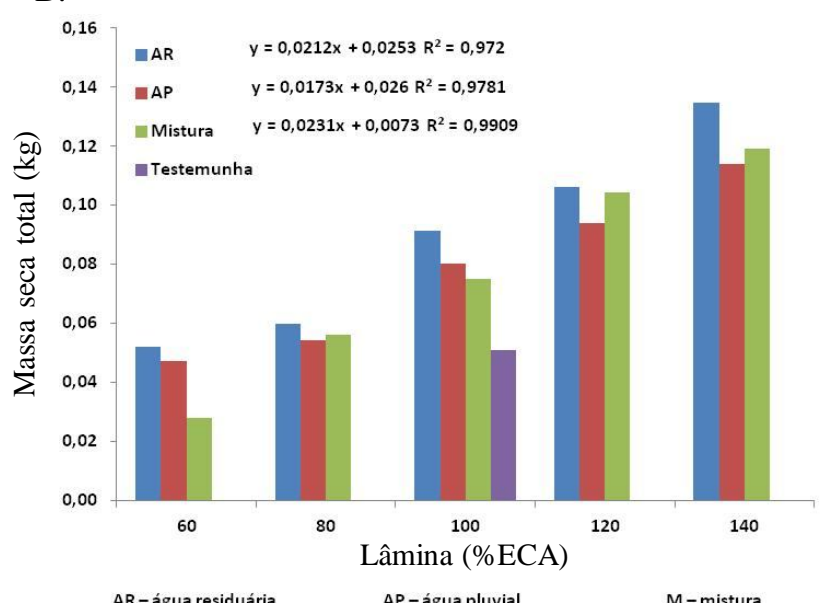

Figura 1. Efeito dos diferentes tipos de água e lâminas de irrigação na massa seca da folha (A), parte aérea (B), subterrânea (C) e total (D) de plantas de helicônia Golden Torch Adrian, 180 dias após o plantio

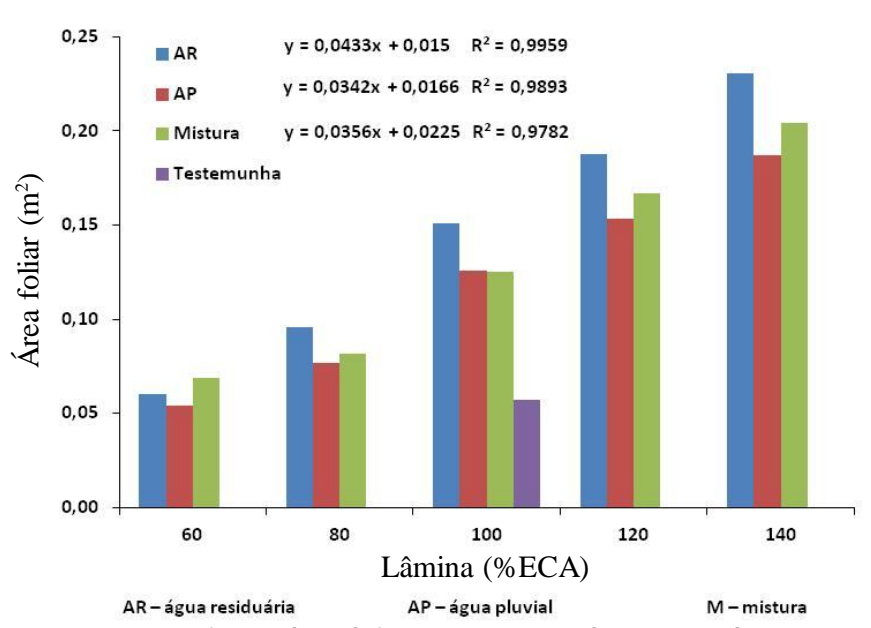

Figura 2. Efeito dos diferentes tipos de água e lâminas de irrigação na área foliar de plantas de helicônia Golden Torch Adrian, 180 dias após o plantio

\section{Macronutrientes}

Os valores médios dos macronutrientes presentes nas folhas de helicônia estão apresentados na Tabela 4; para os teores de $\mathrm{N}$ não houve diferença significativa entre os tipos de água analisada, nem quando comparados com o tratamento testemunha, que apresentou teor de $25,70 \mathrm{~g} \mathrm{~kg}^{-1}$. Mills \& Jones (1996) apresentam os níveis ótimos de macro e micronutrientes para plantas de helicônia do grupo Psittacorum; observa-se, entretanto, que os teores de nitrogênio encontrados nas plantas estão maiores que os recomendados.

Sousa (2006) avaliando o efeito do calcário dolomítico em plantas de helicônia (Heliconia psittacorum x $H$. spathocircinata) cultivar Golden Torch encontrou níveis semelhantes de $\mathrm{N}$ nas folhas não estando, também, dentro do nível adequado da recomendação citada. Cerqueira et al. (2008) avaliando o uso de efluente e Castro (2007) avaliando a deficiência de macronutrientes na mesma cultura, também encontraram níveis acima da recomendação.

Marenco \& Lopes (2005) discorrem a respeito da relação do $\mathrm{N}$ com outros elementos e que a proporção de N/P deve ser em torno de 10-12; foi observado, entretanto, um valor de 22,31 em que o autor cita que valores acima de 16 implicam em um indicativo de deficiência de $\mathrm{P}$; para os teores de fósforo observa-se que as plantas irrigadas com água residuária e mistura apresentaram teores mais altos, diferindo estatisticamente das plantas irrigadas com água pluvial porém os teores encontrados estão abaixo da recomendação. Os teores encontrados estão também abaixo dos níveis encontrados por Cerqueira et al. (2008) para helicônia, Borges \& Caldas (2004) e Damatto Júnior et al. (2006) para a cultura da bananeira e, ainda da faixa recomendada por Silva \& Rodrigues (2001) para bananeira, que varia de 1,8 a 2,7 $\mathrm{g} \mathrm{kg}^{-1}$. Os tratamentos também não diferiram da testemunha, que apresentou valor médio de $1,17 \mathrm{~g} \mathrm{~kg}^{-1}$. A disponibilidade de $\mathrm{P}$ para os vegetais é determinada em grau razoável, pela forma iônica desse elemento e esta determinada pelo $\mathrm{pH}$ da solução do solo em que o íon é encontrado.

Os teores de potássio não apresentaram diferença significativa entre os tipos de água e variaram de 17,42 a 18,77 g 
Tabela 4. Teores médios dos macronutrientes nas folhas de helicônia

\begin{tabular}{|c|c|c|c|c|c|c|c|}
\hline \multirow{2}{*}{ Tipo de água } & \multicolumn{5}{|c|}{ Lâmina (\% ECA) } & \multirow{2}{*}{ Média } & \multirow{2}{*}{ Nível ótimo* } \\
\hline & 60 & 80 & 100 & 120 & 140 & & \\
\hline \multicolumn{8}{|c|}{$\mathrm{N}\left(\mathrm{g} \mathrm{kg}^{-1}\right)$} \\
\hline Água residuária & 24,32 & 26,36 & 27,10 & 25,12 & 24,96 & $25,57 \mathrm{a}$ & \\
\hline Água pluvial & 26,37 & 26,51 & 21,95 & 26,96 & 25,54 & $25,47 \mathrm{a}$ & $16,7-17,9$ \\
\hline Mistura & 24,55 & 28,00 & 26,63 & 25,37 & 27,58 & $26,42 \mathrm{a}$ & \\
\hline Média & 25,08 & 26,96 & 25,23 & 25,82 & 26,03 & & \\
\hline Testemunha & & & 25,70 & & & $25,70 \mathrm{a}$ & \\
\hline \multicolumn{8}{|c|}{$P\left(g_{k g}^{-1}\right)$} \\
\hline Água residuária & 1,20 & 1,15 & 1,18 & 1,28 & 1,20 & $1,20 \mathrm{a}$ & \\
\hline Água pluvial & 1,17 & 1,26 & 0,44 & 0,51 & 1,63 & $1,00 \mathrm{~b}$ & $2,7-3,8$ \\
\hline Mistura & 1,18 & 1,31 & 1,25 & 1,27 & 1,37 & $1,28 \mathrm{a}$ & \\
\hline Média & 1,18 & 1,24 & 0,96 & 1,02 & 1,40 & & \\
\hline Testemunha & & & 1,17 & & & $1,17 \mathrm{a}$ & \\
\hline \multicolumn{8}{|c|}{$\mathrm{K}\left(\mathrm{g} \mathrm{kg}^{-1}\right)$} \\
\hline Água residuária & 17,49 & 17,57 & 17,71 & 18,35 & 17,39 & $17,70 \mathrm{a}$ & \\
\hline Água pluvial & 16,02 & 17,77 & 14,87 & 19,30 & 18,75 & $17,34 \mathrm{a}$ & $12,7-21,3$ \\
\hline Mistura & 17,98 & 18,86 & 19,02 & 19,08 & 20,28 & $19,04 \mathrm{a}$ & \\
\hline Média & 17,17 & 18,06 & 17,20 & 18,91 & 18,80 & & \\
\hline Testemunha & & & 18,64 & & & $18,64 \mathrm{a}$ & \\
\hline \multicolumn{8}{|c|}{$\mathrm{Ca}\left(\mathrm{g} \mathrm{kg}^{-1}\right)$} \\
\hline Água residuária & 7,62 & 7,54 & 7,38 & 7,26 & 8,34 & $7,63 \mathrm{a}$ & \\
\hline Água pluvial & 6,74 & 6,46 & 7,44 & 6,63 & 6,88 & $6,83 \mathrm{a}$ & $7,5-8,1$ \\
\hline Mistura & 7,25 & 7,52 & 7,48 & 6,80 & 7,00 & $7,21 \mathrm{a}$ & \\
\hline Média & 7,20 & 7,17 & 7,44 & 6,90 & 7,41 & & \\
\hline Testemunha & & & 7,34 & & & $7,34 \mathrm{a}$ & \\
\hline \multicolumn{8}{|c|}{$\operatorname{Mg}\left(\mathrm{g} \mathrm{kg}^{-1}\right)$} \\
\hline Água residuária & 4,11 & 3,88 & 3,95 & 3,99 & 4,19 & $4,02 \mathrm{a}$ & \\
\hline Água pluvial & 3,75 & 3,73 & 3,33 & 3,79 & 3,52 & $3,62 \mathrm{~b}$ & $3,3-3,8$ \\
\hline Mistura & 3,88 & 3,66 & 3,99 & 4,11 & 4,32 & $3,99 a b$ & \\
\hline Média & 3,91 & 3,76 & 3,76 & 3,96 & 4,01 & & \\
\hline Testemunha & & & 3,86 & & & $3,86 a b$ & \\
\hline
\end{tabular}

Médias seguidas das mesmas letras não diferem entre si pelo teste de Tukey $(P<0,05)$

* Mills \& Jones (1996)

$\mathrm{kg}^{-1}$ dentro, portanto, da faixa descrita por Mills \& Jones (1996), que é de 12,7 a 21,3 $\mathrm{g} \mathrm{kg}^{-1}$, também não diferiu da testemunha que apresentou valor médio de $18,64 \mathrm{~g} \mathrm{~kg}^{-1}$. De acordo com Boaretto et al. (1999), as concentrações de K adequadas para a

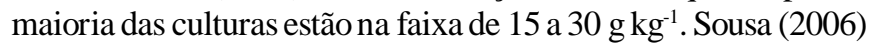
estudando a helicônia Golden Torch encontrou, para esta variável, valores abaixo da recomendação; Cerqueira et al. (2008) porém, também avaliando a helicônia Golden Torch, indicaram valores dentro da faixa recomendada. Feigin et al. (1984), utilizando efluente e água tratada na irrigação de algodão não observaram diferença significativa entre os tipos de água para teores de N, P e K verificando, porém, um acúmulo de K nas plantas irrigadas com efluente.

O cálcio não apresentou diferença significativa entre os tipos de água e também não diferiram da testemunha $\left(7,34 \mathrm{~g} \mathrm{~kg}^{-1}\right)$; contudo, apenas as plantas irrigadas com água residuária mostraram teores dentro da faixa recomendada enquanto as demais apresentaram valores menores que a recomendação.

O magnésio apresentou diferença entre os tipos de água; os maiores teores foram observados nas plantas que receberam água residuária e a mistura, estando esses valores um pouco acima da recomendação, as plantas irrigadas com água pluvial apresentaram valores dentro da faixa recomendada e os tratamentos não diferiram da testemunha a qual apresentou valor de $3,86 \mathrm{~g} \mathrm{~kg}^{-1}$. Medeiros et al. (2008), estudando a influência da aplicação de cinco lâminas de água residuária sobre o "status" nutricional do cafeeiro, notaram que a adoção dos manejos não foi efetiva para elevar as concentrações dos macro e micronutrientes nas folhas, a níveis considerados adequados para a cultura do cafeeiro porém se verificou que a adoção do manejo com água residuária foi mais efetiva na melhoria do estado nutricional do cafeeiro que o manejo convencional.

\section{Micronutrientes}

Apresentam-se na Tabela 5, os teores de micronutrientes nas folhas de helicônia em função dos tipos de água; verificase, para os teores de Fe, que houve diferença significativa entre os tipos de água em que a mistura apresentou os maiores teores com 217,45 mg kg-1; o tratamento testemunha não diferiu das água residuária e pluvial com valor médio de 188,89 mg kg-1; observa-se, entretanto, que os valores estão muito acima dos recomendados por Mills \& Jones (1996). Segundo Malavolta et al. (1997) a absorção de ferro é influência dos cátions K, Ca e $\mathrm{Mg}$, visto que no solo eles favorecem o aumento do $\mathrm{pH}$ promovendo a redução da absorção de ferro pelas plantas, pois formam compostos na forma de $\mathrm{Fe}^{3+}$, que são insolúveis.

Para os teores de Zn não houve diferença significativa entre os tipos de água; verifica-se, porém, que apenas as plantas irrigadas com a mistura apresentaram teor de zinco dentro da faixa recomendada e o tratamento testemunha não diferiu dos demais tipos de água, com valor médio de $12,57 \mathrm{mg} \mathrm{kg}^{-1}$; para o cobre a diferença foi significativa entre os tipos de água, em 
Tabela 5. Teores médios dos micronutrientes nas folhas de helicônia sob diferentes tipos de água e lâminas de irrigação

\begin{tabular}{|c|c|c|c|c|c|c|c|}
\hline \multirow{2}{*}{ Tipo de água } & \multicolumn{5}{|c|}{ Lâmina (\% ECA) } & \multirow{2}{*}{ Média } & \multirow{2}{*}{ Nível ótimo* } \\
\hline & 60 & 80 & 100 & 120 & 140 & & \\
\hline $\begin{array}{l}\text { Água residuária } \\
\text { Água pluvial } \\
\text { Mistura } \\
\text { Média } \\
\text { Testemunha }\end{array}$ & $\begin{array}{l}124,04 \\
125,02 \\
209,85 \\
152,97\end{array}$ & $\begin{array}{l}130,92 \\
114,21 \\
305,82 \\
183,65\end{array}$ & $\begin{array}{c}\mathrm{Fe}\left(\mathrm{mg} \mathrm{kg}^{-1}\right) \\
137,80 \\
201,67 \\
290,10 \\
209,85 \\
188,89\end{array}$ & $\begin{array}{l}123,06 \\
190,86 \\
147,62 \\
153,85\end{array}$ & $\begin{array}{l}124,04 \\
178,08 \\
133,87 \\
145,33\end{array}$ & $\begin{array}{l}127,97 \mathrm{~b} \\
161,97 \mathrm{~b} \\
217,45 \mathrm{a} \\
188,89 a b\end{array}$ & $30-40$ \\
\hline $\begin{array}{l}\text { Água residuária } \\
\text { Água pluvial } \\
\text { Mistura } \\
\text { Média } \\
\text { Testemunha }\end{array}$ & $\begin{array}{l}12,27 \\
14,94 \\
11,78 \\
12,99\end{array}$ & $\begin{array}{l}13,45 \\
14,49 \\
20,13 \\
16,02\end{array}$ & $\begin{array}{c}\mathrm{Zn}\left(\mathrm{mg} \mathrm{kg}^{-1}\right) \\
12,57 \\
11,97 \\
14,93 \\
13,16 \\
12,57 \\
\end{array}$ & $\begin{array}{l}16,42 \\
16,27 \\
19,83 \\
17,51\end{array}$ & $\begin{array}{l}18,49 \\
16,12 \\
17,60 \\
17,41\end{array}$ & $\begin{array}{l}14,64 \mathrm{a} \\
14,76 \mathrm{a} \\
16,85 \mathrm{a} \\
\\
12,57 \mathrm{~b} \\
\end{array}$ & $16-23$ \\
\hline $\begin{array}{l}\text { Água residuária } \\
\text { Água pluvial } \\
\text { Mistura } \\
\text { Média } \\
\text { Testemunha }\end{array}$ & $\begin{array}{l}6,54 \\
3,61 \\
1,98 \\
4,04\end{array}$ & $\begin{array}{l}3,61 \\
1,17 \\
1,66 \\
2,15\end{array}$ & $\begin{array}{c}\mathrm{Cu}\left(\mathrm{mg} \mathrm{kg}^{-1}\right) \\
4,10 \\
3,12 \\
1,66 \\
2,96 \\
5,08 \\
\end{array}$ & $\begin{array}{l}3,61 \\
3,12 \\
1,17 \\
2,63\end{array}$ & $\begin{array}{l}3,61 \\
1,66 \\
1,17 \\
2,15\end{array}$ & $\begin{array}{l}4,29 a \\
2,54 \mathrm{~b} \\
1,53 \mathrm{c} \\
5,08 \mathrm{a}\end{array}$ & $5-8$ \\
\hline $\begin{array}{l}\text { Água residuária } \\
\text { Água pluvial } \\
\text { Mistura } \\
\text { Média } \\
\text { Testemunha }\end{array}$ & $\begin{array}{l}493,93 \\
605,60 \\
484,40 \\
527,97\end{array}$ & $\begin{array}{l}510,44 \\
665,62 \\
724,59 \\
633,55\end{array}$ & $\begin{array}{c}\text { Mn }\left(\mathrm{mg} \mathrm{kg}^{-1}\right. \\
585,10 \\
532,48 \\
624,63 \\
580,74 \\
409,09\end{array}$ & $\begin{array}{l}685,55 \\
545,17 \\
519,30 \\
583,34\end{array}$ & $\begin{array}{l}532,88 \\
401,23 \\
480,34 \\
471,49\end{array}$ & $\begin{array}{l}561,58 \mathrm{a} \\
550,02 \mathrm{a} \\
566,65 \mathrm{a} \\
409,09 \mathrm{~b}\end{array}$ & $26-93$ \\
\hline
\end{tabular}

Médias seguidas das mesmas letras não diferem entre si pelo teste de Tukey $(P<0,05)$

* Mills \& Jones (1996)

que a água residuária apresentou maiores teores estando, entretanto, abaixo da recomendação. $\mathrm{O}$ tratamento testemunha, tal como a água residuária, diferiu estatisticamente dos outros tipos de água apresentando valor médio de $5,08 \mathrm{mg} \mathrm{kg}^{-1}$.

Para Mn, não houve diferença significativa entre os tipos de água, no entanto, todas foram superiores em relação a testemunha $\left(409,09 \mathrm{mg} \mathrm{kg}^{-1}\right)$ porém, assim como para o Fe, os valores foram muito acima do recomendado. Segundo Pavan et al. (1982) a toxidez do manganês é um dos principais fatores que prejudicam o crescimento das plantas; o excesso deste micronutriente geralmente afeta mais severamente a parte aérea do que as raízes e, aparentemente, as plantas absorvem e transportam o manganês em quantidades excessivas, o que resulta em acúmulo nas folhas.

Os teores de micronutrientes encontrados se assemelham aos referidos por Cerqueira et al. (2008) e Sousa (2006) para a cultura da helicônia. Ressalta-se ainda que o aumento das lâminas não foi suficiente para proporcionar acréscimo nos teores de $\mathrm{Zn}$ e $\mathrm{Cu}$ nas folhas.

\section{ConClusõEs}

1. As parcelas irrigadas com água residuária e mistura apresentaram resultados similares e superiores aos da irrigadas com água pluvial e testemunha quanto à altura, numero de folhas e diâmetro do pseudo caule.

2. Não foi observada interação entre os tipos de água e as lâminas de água aplicadas.

3. A irrigação com água residuária e mistura apresentaram resultados similares, foram superiores aos da irrigação com água pluvial para o teor foliar de $\mathrm{P}$ e apresentaram efeito significativo entre a irrigação com água pluvial e testemunha para teor de $\mathrm{Mg}$; para os macronutrientes $\mathrm{N}, \mathrm{K}$, Ca não houve efeito significativo entre os tratamentos;

4. O uso de água residuária e pluvial resultou em acréscimo de micronutrientes $\mathrm{Fe}$ e $\mathrm{Mn}$ nas folhas, acima dos teores recomendados para a cultura da helicônia.

\section{LITERATURA CITADA}

Aiello, R.; Cirelli, G. L.; Consoli, S. Effects of reclaimed wastewater irrigation on soil and tomato fruits: A case study in Sicily (Italy). Agricultural Water Management, v.93, p.6572, 2007.

Ammary, B. Y. Wastewater reuse in Jordan: Present status and future plans. Desalination, v.211, p.164-176, 2007.

Ayers, R. S.; Westcot, D. W. A qualidade da água na agricultura. Campina Grande: UFCG. 1991.218p.

Boaretto, A. E.; Chitolina, J. C; Raij, B. van; Silva, F. C.; Tedesco, M. J.; Carmo, C. A. F. de S. Amostragem, acondicionamento e preparação das amostras de plantas para analise química. In: Silva, F. C. (org.). Manual de análises químicas de solos, plantas e fertilizantes. Brasília: Embrapa, 1999.370p.

Borges, A. L.; Caldas, R. C. Teores de nutrientes nas folhas de bananeira, cv. Pacovan, sob irrigação. Ciência e Agrotecnologia, v.28, p.1099-1106, 2004.

Carvalho, S. R. L.; Rezende, J. O.; Fernandes, J. C.; Pereira, A.P. Caracterização e avaliação de leguminosas e gramíneas com alto poder relativo de penetração de raízes em solo coeso dos tabuleiros costeiros do recôncavo baiano - Etapa I. Magistra, v.14, p.163-1692002. 
Castro, A. C. R. Deficiência de macronutrientes em Helicônia 'Golden Torch'. 2007. 102p. Recife: UFRPE.

Castro, A. C. R. de; Costa, V. L.A. S. da; Castro, M. F. A. de; Aragão, F. A. S. de; Willadino, L. G. Hastes florais de helicônia sob deficiência de macronutrientes. Pesquisa Agropecuária Brasileira, v.42, p.1299-1306, 2007.

Cerqueira, L. L.; Fadigas, F. de S.; Pereira, F. A.; Gloaguen, T. V.; Costa, J. A. Desenvolvimento de Heliconia psittacorum e Gladiolus hortulanus irrigados com águas residuárias tratadas. Revista Brasileira e Engenharia Agrícola e Ambiental, v.12, p.606-613, 2008.

Damatto Júnior, E. R. Bôas, R. L. V.; Leonel, S.;. Fernandes, D. M. Avaliação nutricional em folhas de bananeira 'Prata-Anã' adubadas com composto orgânico. Revista Brasileira de Fruticultura, v.28, p.109-112, 2006.

D’Angiolella, G. L. B.; Castro Neto, M. T.; Coelho, E. F. Tendências climáticas para os Tabuleiros Costeiros da região de Cruz das Almas, BA. In: Congresso Brasileiro de Engenharia Agrícola, 27, 1998, Poços de Caldas. Anais... Lavras, SBEA, 1998, v.1, p.43-45.

Feigin, A.; Vaisman, I.; Bielorai, H. Drip irrigation of cotton with treated municipal effluents: II. Nutrient availability in soil. Journal of Environmental Quality, v.13, p.234-238, 1984.

Figueiredo, F. P.; Oliveira, F. G.; Pereira, M. C. T. Efeitos de diferentes lâminas de irrigação na produtividade de bananeira 'Prata Anã' cultivada no norte de Minas Gerais. Revista Ceres, v.52, p.429-433, 2005.

Galbiatti, J. A.; Cavalcante, I. H. L.; Ribeiro, A. G.; Cavalcante, M. Z. B. Fertirrigação e qualidade de água de irrigação no crescimento e desenvolvimento de alface. Scientia Agraria, v.8, p.185-192, 2007.

Kämpf, A. N.; Takane, R. J.; Siqueira, P. T. V. Floricultura: Técnicas de preparo de substratos. 1.ed. Brasília: LK Editora e Comunicação, 2006. v.1, 132p.

Malavolta, E; Vitti, G. C.; Oliveira, S. A. Avaliação do estado nutricional das plantas: Princípios e aplicações. Piracicaba: Associação Brasileira para Pesquisa da Potassa e do Fosfato, 1997, 319p.

Marenco, R. A.; Lopes, N. F. Fisiologia vegetal: Fotossíntese, respiração, relações hídricas e nutrição mineral, Viçosa: Editora UFV. 2005. 451p.

Medeiros, S. S.; Soares, A. A.; Ferreira, P. A.; Neves, J. C. L.; Souza, J. A. Utilização de água residuária de origem doméstica na agricultura: Estudo do estado nutricional do cafeeiro. Revista Brasileira e Engenharia Agrícola e Ambiental, v.12, p.109-115, 2008.
Medeiros, S. S.; Soares, F. A. L.; Gheyi, H. R.; Fernandes, P. D. Uso de água residuária de origem urbana no cultivo de gérberas: Efeitos nos componentes de produção. Revista de Engenharia Agrícola, v.27, p.569-578, 2007.

Mills, H. A.; Jones, J. B. Plant analysis handbook II: A practical sampling, preparation, analysis and interpretation guide. Athens: MicroMacro, 1996. 456p.

Murray, A.; Ray, I. Wastewater for agriculture: Areuse-oriented planning model and its application in peri-urban China. Water Research, v.44, p. 1667-1679, 2010.

Nobre, R. G.; Gheyi, H. R.; Soares, F. A. L.; Andrade, L. de O.; Nascimento, E. C. S. Produção do girassol sob diferentes lâminas com efluentes domésticos e adubação orgânica. Revista Brasileira e Engenharia Agrícola e Ambiental, v.14, p.747-754, 2010.

Pavan, M.A.; Bingham, F.T.; Pratt, P.F. Toxicity of aluminum to coffee in Ultisols and Oxisols amended with $\mathrm{CaCO}_{3}$ and $\mathrm{CaSO}_{4}$. Soil Science Society of America Journal, v.46, p.12011207, 1982.

Qadir, M.; Wichelns, D.; Raschid-Sally, L.; McCornick, P.G.; Drechsel, P.; Bahri, A.; Minhas, P.S. The challenges of wastewater irrigation in developing countries. Agricultural Water Management, v. 97, p.561-568, 2010.

Rutkowski, T.; Raschid-Sally, L.; Buechler, St. Wastewater irrigation in the developing world-Two case studies from the Kathmandu Valley in Nepal. Agricultural Water Management, v.88, p.83-91, 2007.

Santos, M. R. A; Timbó, A. L. O.; Carvalho, A. C. P. P.; Morais, J. P. S. Estudo de adubos e substratos orgânicos no desenvolvimento de mudas micropropagadas de helicônia. Horticultura Brasileira, v.24, p.273-278, 2006.

Silva, E. B.; Rodrigues, M. G. V. Levantamento nutricional dos bananais da região do norte de Minas Gerais pela análise foliar. Revista Brasileira de Fruticultura, v.23, p.695-698, 2001.

Sousa, G. O. Efeito da calagem no crescimento e nutrição de plantas de helicônia (Heliconia psittacorum x $H$. spathocircinata Arist.) cultivar Golden Torch, em Latossolos amarelos no estado do Pará. 2006. 114p. Belém: UFRA.

Teixeira, L. A. J.; Natale, W.; Martins, A. L. M. Nitrogênio e potássio via fertirrigação e adubação convencional-estado nutricional das bananeiras e produção de frutos. Revista Brasileira de Fruticultura, v.29, p.153-160, 2007.

Walker, C.; Lin, H. S. Soil property changes after four decades of wastewater irrigation: A landscape perspective. Catena, v.73, p.63-74, 2008. 